\title{
EL PLAZO EN LA PRESCRIPCIÓN DE LAS INFRACCIONES Y SANCIONES ADMINISTRATIVAS ANTE EL PRINCIPIO DE PROPORCIONALIDAD*
}

\author{
THE STATUTE OF LIMITATIONS FOR ADMINISTRATIVE \\ INFRACTIONS AND SANCTIONS AND THE PRINCIPLE \\ OF PROPORTIONALITY
}

\section{EduARdo Cordero Q.*}

\begin{abstract}
RESUMEN: Este trabajo tiene por objeto determinar los criterios para resolver el problema del plazo de la prescripción de las infracciones y sanciones administrativas a partir del principio de proporcionalidad, ante la ausencia de una norma general. Se sostiene que no resulta admisible un plazo uniforme, soslayando la gravedad de la infracción. Así, el marco de referencia está constituido por la legislación administrativa y penal, que es la matriz disciplinar más cercana del régimen de los ilícitos administrativos.
\end{abstract}

Palabras claves: Prescripción, infracción administrativa, sanción administrativa, proporcionalidad.

ABSTRACT: The purpose of the investigation is to determine the criteria for resolving the problem of the statute of limitations for administrative infractions and sanctions based on the principle of proportionality, when there is no general rule. It is stated that a uniform deadline is not admissible, ignoring the seriousness of the infringement. In this case, the frame of reference is constituted by the administrative and penal legislation, which is the closest disciplinary matrix of the regime of administrative infractions.

Keywords: Statute of limitations, administrative infractions, administrative sanctions, proportionality.

\section{INTRODUCCIÓN}

El tema de la prescripción de las infracciones y sanciones administrativas se ha transformado para varios autores en una cuestión capital, pues a través de ella se ha intentado resolver la disputa dogmática en torno a la naturaleza y el régimen jurídico que le es aplicable, cuestión que tampoco es pacífica en el Derecho comparado ${ }^{1}$. Por eso no es de extrañar que se afirme que el Derecho administrativo sancionador continúa siendo un campo del

\footnotetext{
Doctor en Derecho, Profesor Titular de Derecho Administrativo de la Pontificia Universidad Católica de Valparaíso. Código Orcid 0000-0002-8433-5582. Dirección postal: Facultad de Derecho, Pontificia Universidad Católica de Valparaíso, Casilla postal 4059, Valparaíso, Chile. Correo electrónico: eduardo.cordero@pucv.cl Este trabajo es parte de una investigación financiada por FONDECYT referida al proyecto "Criterios y estándares para el control de la potestad sancionadora de la Administración: análisis de los mecanismos de revisión judicial y administrativa” No 1201868; y del Proyecto DI Consolidado 37.0/2019, de la Vicerrectoría de Investigación y Estudios Avanzados de la Pontificia Universidad Católica de Valparaíso.

1 Vallejo (2016) p. 282.
} 
derecho in fieri, pletórico de lagunas jurídicas que aún encienden polémicas académicas y reclaman respuestas judiciales, pues todavía sigue pendiente el desafío planteado en orden a construir un Derecho administrativo sancionador desde el propio Derecho administrativo, del que forma parte, y desde la matriz constitucional y el Derecho público estatal ${ }^{2}$. Se trata de una tarea de la mayor importancia, pues la solución de un problema jurídico -como la prescripción- que puede resultar secundario, ha de encajar necesariamente en el marco de un sistema que debe dar respuesta a un número mayor de cuestiones.

Esto ha hecho que la discusión aparezca en medio de alternativas radicales y no conciliables, que marca la posición de los juristas, muchas veces develando su "mayor o menor" estatismo o garantismo. Lo singular, es que la discusión no dice relación con todos los aspectos que plantea la prescripción -que son muchos-, sino solo con uno muy acotado, como es el plazo y que, si bien se podría resolver por la vía legal, aquello no daría una respuesta adecuada a una cuestión más profunda, como es el tema del marco regulatorio que debiera dominar el ejercicio de poderes punitivos por parte de la Administración. Además, esto exige que el o los criterios de solución deben ser coherentes tanto ad extra del sistema, esto es, en su relación con los poderes punitivos en general del Estado, como ad intra, dentro del propio sistema infraccional.

En tal sentido, la hipótesis que pretendemos demostrar es que, no existiendo una diferencia ontológica entre los diversos tipos de sanciones que aplican los órganos del Estado, su regulación y aplicación se encuentra sujeta al principio de proporcionalidad reconocido a nivel constitucional, el cual se proyecta al régimen aplicable a la prescripción de los delitos-penas e infracciones-sanciones administrativas, dentro de los cuales se encuentra el plazo, que necesariamente ha de estar asociado a la gravedad de la infracción.

\section{FUNDAMENTOS Y NATURALEZA DE LA PRESCRIPCIÓN DE LA RESPONSABILIDAD ADMINISTRATIVA EN CHILE}

El tiempo es una imagen familiar para toda persona y un fenómeno bien conocido de todo jurista ${ }^{3}$, razón por la cual no resulta ajena a los casos de persecución por los ilícitos administrativos, así como a los problemas en el cumplimiento de las sanciones que se han impuesto, porque dada su naturaleza y entidad, necesariamente ha de producir un efecto extintivo en uno y otro caso. Este fenómeno se expresa jurídicamente a través de la prescripción, cuya justificación histórica se admite por el hecho de ser un mecanismo de pacificación en las relaciones de la comunidad a partir de una consolidación de un estado material, que priva de sentido la exigencia estricta de lo prescrito por el ordenamiento. Así, como el estado de pasividad del acreedor frente a su deudor lleva a su consolidación, produciendo la extinción de las acciones para exigir el cumplimiento de la obligación; la persecución legal de un delito decae cuando el Estado no se ha mostrado diligente o ha carecido de los elementos adecuados para ejercer de forma oportuna una pretensión punitiva.

\footnotetext{
2 Nieto (2011) p. 32.

3 Mayer (2007) p. 645.
} 
En el ámbito de las sanciones administrativas la cuestión se ha planteado en términos similares, pues también pierde sentido y justificación la persecución estatal y la ejecución de sanciones habiendo transcurrido un período razonable. En efecto, en este ámbito cobra particular importancia la oportunidad para ejercer la acción punitiva, considerando que su fundamento se encuentra en la existencia de relaciones sociales más complejas, que exigen una actuación eficaz, oportuna y eficiente por parte de los órganos públicos (plazos breves), pero esa misma complejidad es la que lleva a la Administración a justificar plazos más extensos para reprimir dichas conductas.

El problema puede ser paradójico, ya que las reglas de prescripción exigen de un mandato legal expreso. Sin embargo, la ausencia de una norma general que se haga cargo del tema ha llevado a resultados que son abiertamente disímiles. Así, se ha llegado a sostener que la ausencia de regulación conlleva la imprescriptibilidad de este tipo de responsabilidad $^{4}$, apegada al principio de reserva legal en materia de prescripción ${ }^{5}$. Por otra parte, se ha buscado una norma legal supletoria que permita resolver la cuestión, ya sea la legislación penal, las normas civiles o a las propias normas administrativas como marco de referencia.

En ese contexto, nuestra jurisprudencia ha reconocido el carácter universal de la prescripción, la cual puede operar en todas las disciplinas, salvo que la ley o la índole de la materia determinen lo contrario ${ }^{6}$. Por tanto, es plenamente aplicable en el ámbito de las infracciones administrativas ${ }^{7}$. A su vez, se reitera que la prescripción es una institución que informa todo nuestro ordenamiento jurídico y otorga estabilidad y seguridad jurídica en las relaciones que se generan entre las personas para que no se prolonguen indefinidamente en el tiempo ${ }^{8}$. En la misma línea, a nivel constitucional se ha señalado que la prescripción es una institución común a nuestro sistema, toda vez que se encuentra tanto en el ámbito de las normas de derecho público como de derecho privado' ${ }^{9}$ A su vez, el carácter imprescriptible de ciertas acciones requiere de una declaración legal expresa, ya que es excepcional ${ }^{10}$.

\section{FORMAS DE PRESCRIPCIÓN DE LA RESPONSABILIDAD ADMINISTRATIVA Y SUS EFECTOS}

El paso del tiempo produce la extinción de la responsabilidad administrativa, ya sea que opere la prescripción de la infracción o de la sanción, esto es, la acción de la Administración para perseguir el ilícito administrativo, como la posibilidad de ejecutar la sanción

\footnotetext{
4 En el Dictamen No 35.991 (1982) de Contraloría. Esta jurisprudencia fue dejada sin efecto por el Dictamen No 28.226 (2007). En relación a la responsabilidad disciplinaria, la Contraloría estableció un criterio similar por falta de regulación en el Estatuto Administrativo: Dictámenes N ${ }^{\text {os }} 97.010$ (1965); 80.098 (1972); 52.562 (1975) y 40.050 (1981).

5 Dictamen No 16.159 (1993).

6 PIZANI Y OTRA CON FISCO (2003).

7 Compañia de Telecomunicaciones de Chile S.A. con Ministerio de TRansportes y TeleComunicaciones (2012).

8 Oyarzún con Sociedad Pesquera del Mar Antartico S.A. (2015); Pizani y otra con Fisco (2003); Empresa

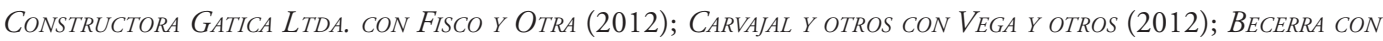
REYES (2012); GUERRERO CON BERSANO Y OTRO (2017), entre otras.

9 Gatica Y OTRA CON SOTO (2010). Artículos 15 y 16 del Decreto Ley No 2.695, Rol No 1.298 .

10 Pizani y otra CON Fisco (2003).
} 
una vez ya impuesta. Si bien esta distinción proviene de la regulación penal ${ }^{11}$, aquella ha sido asumida por la doctrina ${ }^{12}$, la jurisprudencia administrativa ${ }^{13} \mathrm{y}$, en algunos casos, en la regulación legal ${ }^{14}$.

En tal sentido, vamos a entender que la prescripción es una forma de extinción de la responsabilidad administrativa o infraccional en la que ha incurrido una persona por el transcurso del tiempo. De este modo, la responsabilidad prescribirá por el cumplimiento del plazo de que dispone la Administración para dirigir su actuación en contra el responsable de aquella, o no se ha ejecutado o reanudado la ejecución de una sanción desde que el acto que la impone causa ejecutoriedad ${ }^{15}$. Así, lo que se extingue es la responsabilidad administrativa por la infracción cometida, junto a la acción de la Administración para perseguir ${ }^{16}$ o ejecutar la sanción impuesta. Por lo tanto, la infracción en sí misma no se extingue, dado que constituye un hecho inalterable materialmente. Por lo demás, la prescripción supone la inexigibilidad de la sanción, sin embargo, no elimina la infracción cometida, debidamente perseguida y declarada, lo cual seguirá constando en el expediente administrativo ${ }^{17}$.

Ahora bien, cumplidos los plazos de prescripción, la responsabilidad administrativa se extingue ope legis. Esto tiene aparejada una serie de consecuencias:

a) La autoridad administrativa o judicial tiene el deber de declararla de oficio. Así, no se iniciará el procedimiento de ejecución; se pondrá término al ya iniciado ${ }^{18}$ o cesará con los actos para la ejecución de la sanción impuesta. Además, deberá ordenar el archivo de los antecedentes, debiendo notificar de estas actuaciones a los interesados ${ }^{19}$. En el orden judicial, si bien el interesado puede alegarla como acción o excepción, aquello no obsta a que el juez pueda declararla de oficio una vez que ha constatado que concurren los requisitos legales;

b) En la misma línea, la doctrina entiende que tampoco el beneficiario de la prescripción puede renunciar a ella, dado que se trata de una materia de orden público, de carácter indisponible ${ }^{20}$;

\footnotetext{
11 Así el Código Penal distingue entre prescripción de la acción penal (artículo 94) y prescripción de la pena (artículo 97).

12 Nieto (2012) pp. 533-557.

13 Véase Dictamen No 68.014 (2013). Así también se ha hecho la distinción entre prescripción de la infracción, como sucede en el Dictamen No 44.905 (2013), y de la sanción, en el Dictamen No 53.050 (2013).

14 Artículo 61 de la LeY No 21.000 (2007); artículo 15 de la LeY No 18.902 (1990), y artículo 23 de la LEY No 21.130 (1997).

15 CANO (2014) p. 449.

16 BACA (2011) p. 265.

17 Caballero (2010) p. 655.

18 Artículo 14 inciso final y 43 inciso final de la LEY No 19.880 (2003). Se puede tomar como referencia que en materia disciplinaria Contraloría ha sostenido que la prescripción no solo se puede, sino que se debe se declarar de oficio la prescripción, con fundamentos que también resultan aplicables en sede de sanciones gubernativas, Dictamen No 41.239 (2014).

19 SÁNCHEZ (2016) p. 722.

20 Cano (2014) p. 450; De Diego (2009) p. 45; Caballero (1999) p. 443; De palma (2001) p. 555; BaCa (2011) p. 265, entre otros.
} 
c) Por la misma razón, no existe un límite temporal para poder ser alegada dentro del procedimiento administrativo o judicial ${ }^{21}, y$

d) La persecución de una infracción o la imposición de una sanción estando prescrita la responsabilidad administrativa, constituyen actos que adolecen de un vicio de legalidad en los motivos, toda vez que se está castigando o ejecutando por un hecho u omisión respecto del cual no es posible hacerla efectiva ${ }^{22}$.

\section{LA REGULACIÓN DE LA PRESCRIPCIÓN: TENDENCIAS EN EL DERECHO COMPARADOY EN CHILE}

En el Derecho comparado y nacional es posible apreciar ciertos criterios en la regulación de la prescripción de las infracciones administrativas, que es posible sintetizar en los siguientes puntos:

a) Por regla general, las acciones civiles y penales prescriben. Por tal razón, la imprescriptibilidad ha requerido de texto expreso, como sucede en la legislación civil ${ }^{23}$ y penal ${ }^{24}$ o, en algunos casos, a partir de una interpretación jurisprudencial unifor$\mathrm{me}^{25}$. Así, la falta de norma expresa o de un pronunciamiento judicial en tal sentido, colocan en una difícil posición al operador jurídico al momento de pronunciarse a este respecto, pues no resulta posible sostener -ante la falta de regulación legal- la imprescriptibilidad de las infracciones y sanciones administrativas, frente a simples delitos y crímenes que si prescriben. Por otra parte, puede resultar arbitrario la posibilidad de fijar un plazo de prescripción sin contar con un punto de referencia legal que permita sustentar dicha posición.

b) En estas regulaciones se asume la distinción y un tratamiento diverso entre la prescripción de las infracciones y las sanciones administrativas. Si bien la tendencia es aplicar los mismos plazos, la forma en que se puede suspender e interrumpir es diversa ${ }^{26}$.

21 De Diego (2009) p. 45.

22 CANo (2014) p. 450.

${ }^{23}$ Los casos de imprescriptibilidad en el Código Civil son muy pocos: la acción de partición (artículo 317); la acción de demarcación y cerramiento y algunas acciones posesorias por daños entre predios vecinos (artículo 950 inc. $2^{\circ}$ ), y las acciones de reclamación de la filiación (artículos 195 y 320), aunque se reconoce causales de caducidad de la acción en caso de muerte del padre, madre o hijo (artículos 206 y 207). En Derecho comparado, véase Osterling y CASTILlo (2004), pp. 267-274.

24 Así, la Ley No 21.160, que declara imprescriptibles los delitos sexuales cometidos contra menores de edad. A nivel internacional, la Convención sobre la imprescriptibilidad de los crímenes de guerra y de los crímenes de lesa humanidad, adoptada por la Asamblea General en su resolución 2391 (XXIII), de 26 de noviembre de 1968, y el Estatuto de Roma de la Corte Penal Internacional (artículo 29).

${ }_{25}$ Así ha sucedido con la acción de nulidad de derecho público, que la jurisprudencia ha declarado imprescriptible, aunque las acciones patrimoniales derivadas de ella prescriben: AEDO ALARCÓN (2000) y EYZAGUIRRE CID (2007). Por su parte, también se ha consolidado una jurisprudencia en orden a que las acciones civiles que derivan de delitos de lesa humanidad son imprescriptibles. Entre otras, véase ORTEGA FUENTES (2010), ZUCCHINO AGUIRRE (2014) y, más reciente, PIÑONES VEGA (2020) y BuSTOS (2020).

26 Así, $\$ 31$ de la Ley de Infracciones Administrativas de Alemania de 1968 (OWiG). Véase AA.VV. (2018), en particular \$\$31-34 de Ellbogen, pp. 611-670. También el artículo 30 de la Ley 40/2015, de 1 de octubre, de Régimen Jurídico del Sector Público de España (LRJSP). En algunos ordenamientos solo se considera el plazo 
c) El plazo de la prescripción de las infracciones y las sanciones administrativas tiende a utilizar como referencia la regulación penal, considerando como límite el plazo de prescripción más bajo previsto para los delitos o, en su caso, superponiéndose al mismo ${ }^{27}$.

d) Existe una interesante regulación de los plazos en la legislación alemana y española que hace aplicación del principio de proporcionalidad atendiendo a la gravedad de la infracción. Aquello supone, en todo caso, con un régimen uniforme de sanciones (en el caso de Alemania se centra en el monto de las multas) ${ }^{28}$ o en que la legislación sectorial establezca criterios de gravedad (como sucede en España) ${ }^{29}$.

Por su parte, en Chile no contamos con una regulación general de la prescripción, a pesar que es la causa más habitual de extinción de la responsabilidad administrativa. A su vez, en su regulación en particular nos encontramos con diversas situaciones:

a) En algunos casos se carece de toda regulación, como ocurre en materia de seguridad social ${ }^{30}$, sanitaria ${ }^{31}$ y de inteligencia financiera ${ }^{32}$, siendo estas dos últimas las que han planteado mayor discusión en la jurisprudencia;

b) En otras materias se establece una regulación parcial, la cual se limita solo a establecer el plazo de prescripción de la infracción, como sucede en el sector eléctrico ${ }^{33}$, de insolvencia y reemprendimiento ${ }^{34}$, así como en materia tributaria y aduanera, dejando abierta la discusión respecto del régimen de prescripción de las sanciones. La excepción la constituye el sector de mercado financieros ${ }^{35}$, bancos ${ }^{36}$ y servicios sanitarios $^{37}$, que abordan ambos temas, y

\footnotetext{
para las infracciones, pero no de las sanciones (Italia y Perú). Véase Cerbo (2009) pp. 61-90. También AA.VV. (1982) y Giovangnoli y Fratini (2009).

27 En el caso de Italia las infracciones y sanciones administrativas tienen el mismo plazo de prescripción que los delitos que tienen asignadas las penas más bajas (artículos 157 y 173 del Código Penal italiano). En Alemania este plazo de prescripción se ha fijado teniendo presente el último escalón del plazo de prescripción previsto para el ejercicio de la acción penal y su ejecución ( $\$ 78.3$ y $\$ 79.3$ Código Penal alemán). En España se aplica una regla de proporcionalidad en la prescripción, pero que no se coordina necesariamente con las disposiciones el Código Penal, que establece un plazo base de 5 años, excepto los delitos leves y los delitos de injurias y calumnias, que prescriben al año (Artículo 131.1 del Código Penal español). Por último, en Perú existe una superposición considerando que el plazo de prescripción más bajo para los delitos es de 2 años, tanto para ejercer la acción penal y como para la pena (artículo 80 y 86 del Código Penal de Perú).

$28 \$ 31.2 \mathrm{OWiG}$. En este caso se vincula el tiempo de la prescripción con el monto de la multa aplicable, estableciendo plazos de 6 meses, 1, 2 y 3 años.

29 Artículo 30 de la Ley Española 40/2015. Se fijan los plazos en razón de la gravedad de las infracciones y sanciones ( 3 años, 2 años y 6 meses para las infracciones; 3 años, 2 años y 1 año para las sanciones).

30 Ley No 16.395 de 1966.

31 Regulada en el Código Sanitario.

32 Ley No 19.913 de 2003.

33 Artículo 17 bis Ley No 18.410 de 1985.

34 Artículo 342 Ley No 20.720 de 2014.

35 Artículo 61 Ley No 21.000 de 2017.

36 Artículo 23 Decreto con Fuerza de Ley No 3 de 1997.

37 Artículo 15 Ley No 18.902 de 1990.
} 
c) Por último, hay un grupo en el cual se asume una regulación más o menos completa del tema, como sucede en materia de mercados financieros ${ }^{38}$, educación ${ }^{39}$, medio ambiente ${ }^{40}$ y casinos de juego ${ }^{41}$.

En cuanto a los plazos de prescripción se debe distinguir:

a) En relación con su duración, suele variar entre 3 a 4 años, salvo en educación, donde se establece un plazo de 6 meses;

b) No se distinguen los plazos en relación con la gravedad de la infracción, de manera que es uniforme en cada sector, independiente a la mayor o menor sanción que tenga asignada;

c) Tampoco se regula en todos los casos la suspensión e interrupción de la prescripción, salvo en mercados financieros ${ }^{42}$, casino de juegos ${ }^{43}$, medio ambiente ${ }^{44}$ y educación ${ }^{45}, y$

d) Por último, en algunos casos resulta difícil determinar si estamos frente un plazo de caducidad o prescripción, como sucede en educación ${ }^{46}$, servicios sanitarios ${ }^{47}$ y mercados financieros ${ }^{48}$.

En relación con la forma de computar el plazo, hay supuestos en que solo se considera de forma genérica el hecho infraccional, como sucede en materia de servicios sanitarios ${ }^{49}$, casinos de juego ${ }^{50}$, educación ${ }^{51}$, insolvencia y reemprendimiento ${ }^{52}$; y en otras se mencionan las omisiones, como ocurre en mercados financieros ${ }^{53}$, similar a lo que sucede en el sector bancario ${ }^{54}$ y eléctrico ${ }^{55}$.

En definitiva, en materia de prescripción existen diversos aspectos que no están regulados por la legislación sectorial, uno de los cuales es el plazo, incluyendo la forma en que debe ser computado, la situación de la prescripción de la sanción, así como la posibilidad de la suspensión e interrupción. En este caso solo nos avocaremos a buscar una solución con relación al plazo de prescripción de las infracciones y sanciones.

38 Artículo 61 Ley No 21.000 de 2017

39 Artículo 86 LEY No 20.529 de 2011.

40 Artículo 37 Ley No 20.417 de 2010.

41 Artículo 56 bis Ley No 19.995 de 2005.

42 Artículo 61 Ley No 21.000 de 2017.

43 Artículo 56 bis LeY No 19.995 de 2005.

44 Artículo 37 Ley No 20.417 de 2010.

45 Artículo 86 Ley No 20.529 de 2011.

46 Artículo 86 Ley No 20.529 de 2011.

47 Artículo 15 Ley No 18.902 de 1990.

48 Artículo 61 Ley No 21.000 de 2017.

49 Artículo 15 Ley No 18.902 de 1990.

50 Artículo 56 bis LEY No 19.995 de 2005.

51 Artículo 86 Ley No 20.529 de 2011.

52 Artículo 342 LEY No 20.720 de 2014.

53 Artículo 61 Ley No 21.000 de 2017.

54 Artículo 23 DFL No 3 de 1997, modificado por la LeY No 21.130 de 2019.

55 Artículo 17 bis LeY No 18.410 de 1985. 


\section{EL PRINCIPIO DE PROPORCIONALIDAD Y DERECHO ADMINISTRATIVO SANCIONADOR}

Como ha ocurrido en otros ordenamientos, el principio de proporcionalidad se ha ido consolidando en el Derecho chileno de forma transversal a todas las disciplinas jurídicas, y ha encontrado en la jurisprudencia del Tribunal Constitucional un reconocimiento consolidado a partir de diversas disposiciones contenidas en la Carta fundamental ${ }^{56}$. En términos generales, este principio se traduce en una prohibición de exceso respecto del ejercicio de potestades discrecionales por parte de los poderes públicos, sometiéndose a ciertos límites de razonabilidad. Su origen se encuentra en el Derecho Prusiano de policía ${ }^{57}$, cuando por influencia de la ilustración se rompe con los cánones de la policía clásica, centrado en la inmunidad judicial de los poderes de la autoridad, y se reconoce una esfera de libertad de los individuos que debe ser respetada, reconociéndoles el derecho a pedir protección judicial cuando la autoridad interviene ilegalmente en su esfera personal ${ }^{58}$. Es así como el Tribunal Superior Administrativo de Prusia hizo aplicación de este principio frente a los actos discrecionales dictados en virtud del poder de policía, bajo la expresión de übermassverbot o prohibición de exceso, esto es, como un mecanismo para frenar la arbitrariedad de la autoridad. Por tal razón, este principio es ampliamente reconocido y aceptado por la doctrina administrativa y la jurisprudencia ${ }^{59}$.

Por su parte, en el ámbito del Derecho penal, el principio de proporcionalidad será introducido en la época de la ilustración, particularmente en el proceso de humanización de las penas ${ }^{60}$. Así, será recogido en la Declaración de los Derechos del Hombre y del Ciudadano de 1789, disponiendo que la ley no debe establecer más penas que las estricta y evidentemente necesarias (artículo 8\%). A su vez, la proporcionalidad debe corresponder al adecuado equilibrio entre la reacción penal y sus presupuestos, tanto en el momento de la individualización legal de la pena, como en su aplicación ${ }^{61}$. De esta forma, el control de la proporcionalidad recae tanto en el legislador que determina la pena (proporcionalidad en abstracto), como en el juez que debe aplicarla al caso en particular (proporcionalidad concreta).

En la segunda postguerra, este principio será elevado a nivel constitucional, como un límite del ejercicio del poder público por parte de cualquier órgano del Estado, incluido el legislador. Su desarrollo se encuentra en la jurisprudencia del Tribunal Constitucional Federal de Alemania de la década del cincuenta del siglo pasado ${ }^{62}$, pero su consolidación se alcanza en el marco del proceso de constitucionalización de la Unión Europea (UE), especialmente por la jurisprudencia del Tribunal de Justicia de las Comunidades Europeas (TJ), como un mecanismo de protección de los derechos fundamentales y como un límite

\footnotetext{
56 Arnold, MarTíneZ y Zuñiga (2012).

7 Malagón (2004) y Nieto (1976). Un acabado estudio histórico se puede ver Remmert (1995).

8 Nieto (1976) pp. 48-50.

9 García de Enterría (2016). Una relación de casos se puede ver en Mayer (1982), T. II, pp. 31-36.

60 En la cual destaca el trabajo de Cesare Beccaria "De los delitos y las penas", de 1764.

1 Quintero (1982).

62 Remmert (1995). Las sentencias más relevantes se pueden consultar en SchWabe (2009); Fernández Nieto (2008) p. 283; Covarrubias (2018), y Arnold, Martínez y Zuñiga (2012).
} 
a las potestades de la $\mathrm{UE}^{63}$. Así, comienza una tendencia en orden a fundar la prohibición de exceso en el ejercicio de los poderes públicos en diversos preceptos de la Constitución, respecto todo órgano estatal, como resguardo y garantía de los derechos fundamentales, en el marco del Estado de Derecho, tal como como sucede también en Francia ${ }^{64} y$ España ${ }^{65}$.

En un comienzo se sostuvo la idea de que este principio debía extraerse del Derecho Administrativo para ser incluido directamente en el ámbito del Derecho Constitucional ${ }^{66}$, aunque posteriormente se afirmará que tendría su sede natural en el Derecho Constitucional, desplegando su eficacia normativa principalmente en el ámbito de los derechos fundamentales ${ }^{67}$.

En todo caso, ya sea que se adopte desde el Derecho administrativo -en donde encuentra su origen-, del Derecho penal o del Derecho constitucional, no cabe duda que la proporcionalidad constituye un principio general que necesariamente se impone respecto del ejercicio de poderes sancionadores por parte de los órganos administrativos -como lo ha reconocido la doctrina ${ }^{68}$ y la jurisprudencia nacional ${ }^{69}-y$, más aún, se reconoce a nivel constitucional mediante el control que se hace de la ley al momento de configurar dichas potestades.

\section{PRESCRIPCIÓN Y PROPORCIONALIDAD}

Como se ha señalado, no existe en nuestro ordenamiento una regulación general del plazo de prescripción de las infracciones y sanciones, mientras que no todas las normas especiales la regulan o establecen un plazo uniforme. Por lo tanto, no siendo posible sostener la imprescriptibilidad de estos ilícitos, cabe establecer cuál debiera ser el criterio para determinar el plazo de prescripción en estos casos.

\subsection{LA NECESIDAD DE UN PLAZO DE PRESCRIPCIÓN Y LOS CRITERIOS PARA DETERMINARLO}

El problema de la prescripción de la responsabilidad administrativa debe ser analizada a partir de los fundamentos que justifican su existencia y, especialmente, el sentido que tiene en el marco de un mecanismo que está orientado a la protección de bienes jurídicos supraindividuales o colectivos. En tal sentido, la actuación oportuna y eficaz del Estado a

\footnotetext{
63 Reiner, Martínez y Zuñiga (2012), pp. 73-78.

${ }^{64}$ Carpentier (2009) p. 135.

${ }_{65}$ Así, la Sentencia del Tribunal Constitucional Español 154/2002, de 18 de Julio de 2002. Véase Bon y Maus (2008) p. 157.

66 Krauss (1955) p. 2 y ss.

67 LeRCHe (1961) p. 61 y ss.

68 Aldunate y Cordero (2012) pp. 348 y 358; Cordero (2014) p. 254-259; Arancibia (2014) pp. 134-138; Cordero Vega (2015) pp. 524-526; Osorio (2018) pp. 89-92.

69 La Contraloría ha hecho uso constante de este principio en el ámbito de la responsabilidad disciplinaria, como en los dictámenes Nos. 4.767 y 65.855, de 2012. El Tribunal Constitucional ha aplicado este principio en general en las Sentencias Roles Nos. 226, considerando 47o; 280, considerando $21^{\circ}$; y 519, considerando $19^{\circ}$. En relación con las sanciones administrativas en particular, se puede ver la Sentencia Rol No 1518-2009, considerando $14^{\circ}$. La Corte Suprema también sigue este principio, como en la Sentencia Rol No68.723-2016, considerando $10^{\circ}$.
} 
través de los órganos administrativos para enfrentar y administrar estos riesgos, colocan a la sanción en un lugar secundario, como un instrumento que no necesariamente permitirá reparar el daño causado, sino como la última ratio frente a la imposibilidad de evitar ciertos comportamientos que se consideran lesivos o que configuren una amenaza a los intereses. Así, el hecho de que no exista la disposición para perseguir ciertos ilícitos, no solo puede develar un mal funcionamiento de los órganos públicos, sino también que las medidas que se deben adoptar carezcan de oportunidad, de forma que su materialización aparece en definitiva como un acto arbitrario de la autoridad. En este contexto, cabe preguntarse qué sentido tiene la persecución de determinados ilícitos cuando no existe posibilidad alguna de que el bien jurídico protegido sea lesionado, como sería el hecho de castigar atrasos reiterados en la presentación de una declaración o que una persona haya realizado una actividad sin la respectiva autorización, cuando los impuestos ya están ingresados en arcas fiscales o el infractor no realiza actualmente dicha actividad ni tiene pretensión de hacerlo.

En muchos de estos casos, el problema radica en que legislador establece un amplio abanico de deberes, cuyo incumplimiento los asocia a un sinnúmero de infracciones, muchas de las cuales son muy difíciles cumplir y, además, existe en varios de estos la conciencia que sus destinatarios no tienen un conocimiento cabal de los mismos ${ }^{70}$. Junto con lo anterior, está el deber de la Administración para sancionar determinadas conductas en plazos breves y razonables, pues el paso del tiempo hace que pierda sentido su persecución. Sin embargo, tampoco resulta adecuado establecer plazos tan breves que generen un incentivo en los particulares para ampararse en la clandestinidad, aprovechando los medios y recursos de los cuales disponen, frente a órganos y servicios públicos que no tienen la capacidad de poder controlar y reprimir todos estos ilícitos.

De esta forma, el tiempo con el que cuenta la Administración para perseguir y sancionar estos ilícitos debe responder a una regla razonable de medios, recursos y fines que se deben alcanzar, cuestión que está estrechamente asociada al principio de proporcionalidad.

\subsection{LA PENA O SANCIÓN COMO ELEMENTO PARA DETERMINAR LA GRAVEDAD DE LA CONDUCTA A NIVEL LEGAL Y COMO CRITERIO DE PROPORCIONALIDAD}

En esta tarea el plazo de prescripción debe vincularse con el tema de la proporcionalidad y la gravedad de los ilícitos que tipifica el legislador. Como hemos señalado, no cabe duda que la proporcionalidad constituye un principio general que necesariamente se impone respecto del ejercicio de poderes sancionadores por parte de los órganos administrativos y que es determinante en el tema de la prescripción.

Ahora bien, el elemento que permite establecer que ciertas conductas sean consideradas más o menos graves en relación a otras, solo se puede encontrar en la pena que el propio legislador le asigna. En efecto, aquella constituye el único criterio objetivo que nos podrá indicar cuál es el grado de desvalor que le asigna el ordenamiento jurídico a determi-

\footnotetext{
70 Así se señala que "el repertorio de ilícitos comunitarios, estatales, autonómicos, municipales y corporativos ocupa bibliotecas enteras. No ya un ciudadano cualquiera, ni el jurista más estudioso ni el profesional más experimentado son capaces de conocer las infracciones que cada día pueden cometer". NieTo (2012) p. 27. En el mismo sentido, AlCALDE (2013) pp. 344-350.
} 
nada conducta y, al mismo tiempo, es el único elemento de comparación. Por lo demás, si bien en esta labor la ley está condicionada por la Constitución, el nivel de deferencia que se le ha reconocido por parte del Tribunal Constitucional en esta tarea, hace que el margen de discrecionalidad con el cual dispone sea bastante amplio ${ }^{71}$, por lo que la pena que le asigna constituye un criterio capital. Así, el propio Tribunal Constitucional ha señalado que "[...] el quantum de la pena es el mejor reflejo de la gravedad del delito", al punto de considerarlo como el criterio fundamental para evaluar la proporcionalidad: "[...] Lo que determina la gravedad de un ilícito no es la naturaleza del delito. Dicho parámetro es una medida solo intuitiva para apreciar qué tan grave es un tipo penal. El criterio más objetivo para identificar el nivel de gravedad de un ilícito es, como se señaló, el quantum de la pena"72. Luego nos dirá que “[...] La razón fundamental para considerar que el quantum de la pena es el parámetro representativo de la gravedad del delito radica en que es la medida más objetiva, directa y de mayor impacto para expresar el desvalor social de la conducta"73.

De esta forma, la proporcionalidad de la pena puede ser vulnerada en dos niveles: a) cuando la pena abstracta asignada por el legislador está proscrita por la Constitución o porque en sí misma no resulta idónea, necesaria o proporcional en sentido estricto; y b) cuando corresponde a la pena asignada por el legislador, pero en donde se violenta el principio de igualdad y coherencia, al asociarla con ilícitos que tienen asignadas sanciones similares (igual gravedad), pero que están vinculadas a otras medidas que la hacen más o menos gravosas sin una justificación adecuada.

En definitiva, la gravedad de un ilícito está asociada a la sanción prevista por el ordenamiento, lo cual está necesariamente vinculada a todos los efectos y consecuencias derivados de aquel, ya que el legislador queda condicionado en su regulación por los principios de igualdad y coherencia en la regulación, en el marco del principio de proporcionalidad. Además, y como se ha señalado, la gravedad de la sanción también determina la intensidad de las garantías que tendrá el particular frente al Estado.

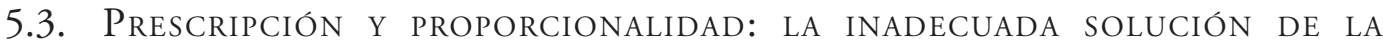 JURISPRUDENCIA Y DE LA DOCTRINA}

Ante la falta de regulación de la prescripción, el problema en nuestro país ha sido la búsqueda de una regla que permitiera suplir dicho vacío, y aquello se ha movido en dos posiciones muy definidas:

a) Asimilar los ilícitos administrativos a las faltas penales, aplicando en este caso las normas de los artículos 94 y 97 del Código Penal, que establecen un plazo de 6 me-

\footnotetext{
71 Honorable Camara de Diputados (2007). Artículo único, No $3^{\circ}$, del proyecto de ley modificatorio de la Ley No 20.084, Rol No 786-2007 (considerando 30). Sobre esta materia véase LOPERA (2011).

72 Recientemente en VARgAS CON Ministerio Público (2018). Inciso segundo del artículo $1^{\circ}$ de la Ley No 18.216, y del artículo 17 B), inciso segundo, de la Ley No 17.798, Rol No 4802-2018 (considerando $9^{\circ}$ ).

73 Gallardo con Ministerio Público (2017). Inciso segundo del artículo $1^{\circ}$ de la Ley No 18.216 , Rol No 2995-2016 (considerando 9º).
} 
ses para la prescripción. Esta ha sido la solución que en un comienzo ha sostenido la Corte Suprema ${ }^{74}$ y la Contraloría General de la República ${ }^{75}$.

b) Entender que se aplica la legislación común, en este caso el artículo 2515 del Código Civil, fijando un plazo de 5 años para la prescripción. Este es el criterio que se ha ido asentado en la jurisprudencia de la Corte Suprema ${ }^{76}$ y que ha seguido recientemente Contraloría, cambiando su jurisprudencia anterior ${ }^{77}$.

En ambos casos, la jurisprudencia parte de la premisa que la prescripción es de carácter universal e indispensable para asegurar criterios de certeza y seguridad en las relaciones jurídicas y, por ello, puede operar en todas las disciplinas que pertenecen al ámbito del Derecho Público ${ }^{78}$. Luego, la opción por una u otra posición responde a fundamentos jurídicos centrados en la naturaleza de los ilícitos administrativos y su identidad con los delitos, así como respecto de cuál sería el Derecho supletorio aplicable: el Código Penal (6 meses) o el Código Civil (5 años); pero también se entregan argumentos que dicen relación con la función que debe cumplir la Administración, tratando de explicar porque el plazo de prescripción debe ser más o menos extenso ${ }^{79}$. El mismo criterio es compartido, en mayor o menor medida, por la doctrina ${ }^{80}$.

74 SCHENKE CON SERVICIO de SALUd (2002). En el mismo sentido, FUENTES CON SEREMI DE SALUD REGIÓN DEL Maule (2005); Empresa ElÉCtrica de Aysén S.A. con Superintendencia de ELECtricidad y Combustibles (2009A); EMPRESA ELÉCTRICA DE AYSÉN S.A. CON SUPERINTENDENCIA DE ELECTRICIDAD Y COMBUSTIBLES (2009B); LABORATORIO MAVER LIMITADA CON ISP (2011); LABORATORIOS RECALCINE S.A. CON ISP (2011); LABORATORIOS RECALCINE S.A. CON ISP (2012); MARTINS Y OTRA CON ISP (2010A); MARTINS Y OTRA CON ISP (2010B); LABORATORIOS RECALCINE S.A. CON ISP (2012); LABORATORIOS RECALCINE S.A. CON ISP (2013); DiRECCIÓN GENERAL DE AGUAS con Sociedad Alto Atacama S.A. (2013); Industria Frigorífica Simunovic S.A. con Comisión de EVALUación

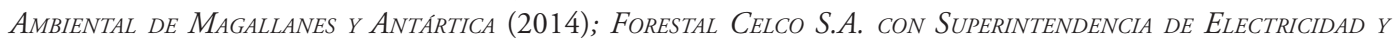
COMBUSTIBLES (2015), ENTRE OTRAS.

75 Dictámenes Nos 14.571 (2005); 28.226 (2007); 30.070 (2008), entre otros.

76 EMPRESA ELÉCTRICA DE ANTOFAGASTA S.A CON SupERINTENDENCIA DE ELECTRICIDAD Y COMBUSTIBLES (2009); EMpREsa ElÉCtrica de Aysen S.A. CON SuperintendenCIa de EleCtricidad Y Combustibles (2009); Albala Y otra CON ISP DE ChILE (2015); Fisco CON IRARRAZABal (2016); FARAH CON SupERINTENDENCIA DE VALORES Y SEGUROS (2016); Promaq Ingeniería y Construcción Limitada con SEREMI de Salud de la Región Metropolitana (2017); Pharmamérica Limitada con ISP (2017); Casino de Juegos Temuco S.A. con Superintendencia de Ca-

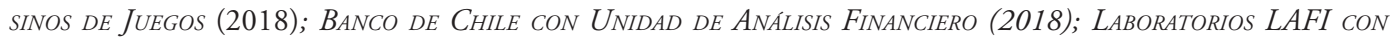
ISP (2018); Compañía Minera Zaldivar Limitada con Secretaria Regional Ministerial de Salud (2018); OpKO ChILE S.A y ALEGRÍa MAdRID CON INSTITUTO DE SALUD PÚbLICA (2019), entre otras.

77 Dictamen No 24.731 (2019).

78 En tal sentido, la Corte Suprema ha sostenido que "[...] debe iniciarse desestimando toda posición que propugne la imprescriptibilidad de las infracciones y sanciones administrativas respecto de aquellas situaciones donde la ley correspondiente no haya establecido de manera expresa un plazo determinado para que opere la prescripción. [...]", ISP CON LABORATORIOS RECALCINE S.A. (2010).

79 Así, en varios pronunciamientos se sostiene que la posición del particular no es la misma que tiene la Administración, por lo que a esta última se le debe exigir un mayor grado de diligencia y esmero, lo que justificaría plazos más breves. Véase LABORATORIOS RECALCINE S.A. CON ISP (2012); MARTINS Y OTRA CON ISP (2010); MARTINS Y OTRA CON ISP (2010); LABORATORIOS RECALCINE S.A. CON ISP (2012); LABORATORIOS RECALCINE S.A. CON ISP (2013). Por otra parte, se sostiene que no resulta procedente "[...] aplicar el plazo de prescripción de las faltas, porque al ser una prescripción de corto tiempo -seis meses- resultaría eludida la finalidad del legislador de dar eficacia a la Administración en la represión de estos ilícitos y la sanción contemplada en la ley carecería de toda finalidad preven-

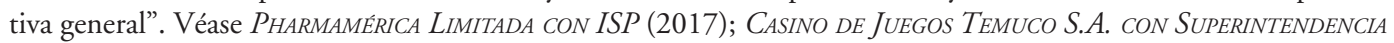
dE CASINos de Juegos (2018); BANCO de ChILE CON UNIDAD DE ANÁLISIS FinANCIERo (2018).

80 Vallejo (2016) y Aróstica (2005) p. 124. 
Sin embargo, el resultado no ha sido del todo satisfactorio, pues el esfuerzo por encontrar una regla para determinar el plazo de prescripción, lleva a un tratamiento uniforme de todas las infracciones administrativas, omitiendo la diversa gravedad que el propio legislador les ha reconocido ${ }^{81}$. En efecto, como se ha dicho, la proporcionalidad es un principio que se aplica plenamente a las infracciones administrativas. A su vez, a pesar de los autores que sostienen la tesis cuantitativa para distinguir entre delitos e infracciones administrativas $^{82}$, no resulta posible sostener a priori que las infracciones administrativas sean menos graves que las penales y viceversa. En efecto, la gravedad de la sanción va a depender de la decisión del legislador, siendo posible que la Administración pueda aplicar sanciones más graves que las que aplique un tribunal, como sucede habitualmente con las multas. Así, el criterio de la gravedad no es determinante y solo opera como un límite para el legislador en los casos en que la Constitución establece una reserva del ámbito jurisdiccional, como sucede con las medidas privativas de libertad ${ }^{83}$. Por tal razón, respecto de sanciones de otra naturaleza, como son las multas, inhabilidades, suspensión para realizar una actividad, etc., es posible que el legislador las radique discrecionalmente en el orden judicial o administrativo, independiente de la gravedad que puedan tener.

Ahora bien, si se proyecta este razonamiento en el ámbito de la prescripción, es de toda lógica que su plazo esté condicionado por la gravedad de la sanción. Este es, por lo demás, el criterio que sigue nuestro Código Penal ${ }^{84}$ y que respecto de las infracciones administrativas es la tendencia en los ordenamientos comparados, como hemos tenido ocasión de ver. A su vez, como bien apunta la jurisprudencia del Tribunal Constitucional, el legislador debe cumplir con un deber de coherencia en la regulación, de forma que la gravedad de la sanción debe estar asociada necesariamente a las demás medidas que están asociadas a ella, como sucede con las penas accesorias, las penas sustitutivas y, en la misma línea, la mayor o menor extensión del plazo de prescripción.

\section{PREMISAS Y CRITERIOS PARA DETERMINAR EL PLAZO DE PRESCRIPCIÓN DE UNA INFRACCIÓN ADMINISTRATIVA}

\subsection{PRESUPUestos PARA LA DETERMinACIÓN DEL PLAZO DE PRESCRIPCIÓN}

Conforme a lo expuesto, la solución al tema de la falta de regulación general de la prescripción, exige algunos criterios de referencia. Más aún, en el caso que sea el propio legislador el asuma la tarea de regularla, tampoco se puede desentender de los límites y crite-

\footnotetext{
${ }^{81}$ La jurisprudencia justifica dicha decisión, pues entiende que el plazo de prescripción es de competencia del legislador, lo que también incluye la determinación de su gradualidad. Véase LABORATORIOS RECALCINE S.A. CON ISP (2012).

82 Este fue el criterio que en un comienzo siguió nuestro Código Penal en su artículo 501, pero que fue superado por la legislación especial. La doctrina siguió un criterio similar ante la imposibilidad de realizar una separación ontológica entre ambos ilícitos. Véase RoXIN (1997) p. 72; JACOBS (1997) pp. 65-66; CerEZO (1975) pp. 159-173 y CURY (2005) pp. 106-107.

83 SANCHeZ y otros CoN SEREMI SALUd (2010). Artículo 169 del Código Sanitario, Rol No 1518 (considerando 22º).

${ }^{84}$ Artículos 94 y 97 del Código Penal.
} 
rios que le impone la propia Constitución, especialmente en lo que dice relación con el respeto de los principios de proporcionalidad, igualdad y de interdicción de la arbitrariedad.

Ahora bien, para dar respuesta a este problema, vamos a partir de las siguientes premisas básicas:

a) Las infracciones o sanciones administrativas no son imprescriptibles. Así, por lo demás, lo ha reconocido nuestra jurisprudencia, y se desprende de lo sostenido en los postulados anteriores: la imprescriptibilidad es una regla excepcional que se aplica a los crímenes de la mayor gravedad, como sucede con los delitos de lesa humanidad y el genocidio. Así, no resulta posible asimilar estos ilícitos a una medida de dicha envergadura.

b) El plazo de prescripción es una materia de reserva legal. Por lo tanto, no es posible que el operador jurídico pueda crear una regla de prescripción al margen de la ley. En todo caso, aquello plantea la paradoja de que siempre deberá encontrar una solución, ya que no es posible tampoco entender que este vacío en la regulación lleve a la imprescriptibilidad.

c) El plazo de prescripción está dominado por el principio de proporcionalidad. Por tal razón, se debe aplicar un plazo que guarde relación con la gravedad de la infracción, considerando el ordenamiento jurídico en su conjunto, asegurando una solución coherente y armónica.

d) No es constitucionalmente admisible establecer un plazo uniforme de prescripción para todas las infracciones y sanciones administrativas que no tengan una regulación especial, sin considerar la gravedad de las mismas. Aquello implica también una vulneración del principio de proporcionalidad, igualdad e interdicción de la arbitrariedad.

e) Por tanto, al momento de determinar dicho plazo, dentro de las soluciones legales vigentes, debe optar por aquella que guarde mayor conformidad con el principio de proporcionalidad (gravedad del ilícito) y que al mismo tiempo permita dar coherencia con las medidas que se pueden adoptar en el orden punitivo, dentro del cual no se puede soslayar el orden penal.

\subsection{LOS ELEMENTOS DE REFERENCIA EN LA DETERMINACIÓN}

Conforme a estas premisas, la solución que en general entrega la jurisprudencia y la doctrina parece del todo inadecuada, ya que un plazo uniforme ya sea breve (6 meses) o más extenso ( 5 años), no atiende al peso específico y la gravedad tiene la infracción cometida y, en su caso, la sanción impuesta. Ahora bien, para encontrar un criterio de solución, resulta conveniente tener como referencia la relación que se da en nuestro ordenamiento entre el orden penal y las disposiciones de policía.

En efecto, como da cuenta nuestra doctrina, los antecedentes de la actividad sancionadora de la Administración se encuentran en la actividad de policía ${ }^{85}$, heredada del

\footnotetext{
85 Nuestros comentaristas de la época solo hacían una mención general a esta figura, sin detenerse en un acabado análisis de los instrumentos con los cuales se hacía efectiva. Véase Prado (1859) pp. 163 y ss.; LETELIER (1907) p. 33, y Amunátegui (1894) p. 221.
} 
Derecho castellano-indiano, pero que lentamente fue adquiriendo sus propios perfiles luego de la independencia ${ }^{86}$, con poderes que llegaron a la adopción de medidas privativas de libertad y de castigo físico ${ }^{87}$. Por tal razón, no son de extrañar las críticas de la existencia de estas atribuciones en manos de la Administración ${ }^{88}$, lo que lleva a una primera etapa en su control y racionalización. Esta se encuentra marcada con la dictación del Código Penal, que en una primera instancia sostiene que este tipo de sanciones no se reputan penas (artículo 20), aunque acto seguido establece que, salvo disposición legal, la autoridad administrativa no establecerá mayores penas que las previstas en dicho cuerpo normativo, aun cuando hayan de imponerse en virtud de atribuciones gubernativas (artículo 501). De esta norma se deduce, al fin y al cabo, que las sanciones gubernativas constituyen penas ${ }^{89}$, aunque sujetas a un límite, esto es, no pueden sobrepasar aquellas previstas en el Código Penal que, a la sazón, comprende ilícitos y sanciones que solo puede aplicar la autoridad judicial. Por tal razón, era de toda lógica que, atendida su gravedad, fueran consideradas bajo el régimen de las faltas, como ilícitos bagatela, incluyendo su plazo de prescripción, como sucede con las infracciones que se sancionan en el ámbito municipal, en los cuales hasta la fecha constituye la regla general: el plazo de prescripción de las infracciones a las ordenanzas municipales que aplican los jueces de policía local es de 6 meses. Además, el artículo 501 también se refiere a "los reglamentos generales o particulares que dictare en lo sucesivo la autoridad administrativa”, avizorando el enorme crecimiento que tendría la potestad reglamentaria ${ }^{90}$. A su vez, manteniendo la coherencia del sistema y a falta de norma especial, el Código Penal dispone que la infracción de reglamento - sea general o particular- tiene una sanción multa, la cual también prescribe en el plazo de 6 meses, al constituir una falta ${ }^{91}$.

Ahora bien, sabemos que en la actualidad la gravedad de las sanciones que se aplican en el orden administrativo superan dicho umbral, por lo que no resulta posible justificar un plazo tan breve en la prescripción de dichas infracciones y sus respectivas sanciones. En este sentido, y ante la falta de regulación, el salto debe ser al peldaño siguiente, esto es, 5 años.

Sin embargo, el problema es determinar cuál sería el umbral que marcará este paso. En efecto, pensamos que la solución es una coordinación entre la legislación administrativa y penal, que parece el ámbito más apropiado para resolver estos asuntos, ya que la matriz

\footnotetext{
86 Véase Gómez (2018), pp. 76-115, en la cual se hace por primera vez un acabado análisis del origen de la potestad sancionadora de la Administración en Chile. También en Gómez (2019).

87 Buena parte de las normas de policía fueron recogidas en la legislación municipal, lo que se puede apreciar en Leyes sobre Organización y Atribuciones de las Municipalidades de 8 de noviembre de 1854; de 12 de septiembre de 1887; y de 22 de diciembre de 1891. Sin embargo, con anterioridad, destaca Ley de Régimen Interior, de 10 de enero de 1844, que integra importantes poderes a los intendentes y gobernadores.

88 Huneeus (1891) p. 231.

89 Así, bien se ha señalado que el artículo 20 del Código Penal no considera a las sanciones administrativas formalmente penas, aunque se reconoce que participan de la misma naturaleza, como señala Cury (2005), p. 107. Por tal razón, el concepto constitucional de pena es más amplio. Véase Rodríguez (1987) p. 123.

90 Cordero (2014) pp. 16-17 y Cordero (2019) pp. 286-287.

91 El artículo 495 No 1 del Código Penal dispone que serán castigados con multa el que contraviniere a las reglas que la autoridad dictare para conservar el orden público o evitar que se altere, salvo que el hecho constituya crimen o simple delito. Aquello es sin perjuicio de la infracción de reglamentos sobre materias específicas, contenidos en los $\mathrm{N}^{\text {os }} 7,13,14,15,20,21,24,27,29$ y 36 de la misma disposición.
} 
disciplinar de las infracciones administrativas encuentra una mayor vinculación en estos sectores en relación con lo que ocurre con la legislación civil.

En este sentido, la regla general en materia de prescripción está marcada por la legislación municipal y de policía, en particular con las infracciones que se tipifican en las ordenanzas municipales y reglamentos. En buena medida, el Código Penal estaba haciendo referencia a dichas disposiciones al momento de establecer un límite a las sanciones que se podía imponer y que pasaban a integrar el abanico de faltas en nuestro sistema, ya que las municipalidades asumieron las facultades de policía en el ámbito local. Por su parte, actualmente la Ley Orgánica Constitucional de Municipalidades dispone que las ordenanzas serán normas generales y obligatorias aplicables a la comunidad. Además, en ellas se pueden establecer multas para los infractores, cuyo monto no excederá de 5 unidades tributarias mensuales, las que serán aplicadas por los juzgados de policía local correspondientes (artículo 12). De esta forma, aquí encontramos un punto de referencia interesante que puede marcar un diverso plazo de prescripción para las infracciones administrativas como regla general.

Otra alternativa es tomar el propio Código Penal y hacer la relación con la pena de multa que él mismo regula. En efecto, dicho cuerpo normativo considera a las multas como una pena común para los crímenes, simples delitos y faltas (artículo 21). Así, se dispone que "La cuantía de la multa, tratándose de crímenes, no podrá exceder de treinta unidades tributarias mensuales; en los simples delitos, de veinte unidades tributarias mensuales, y en las faltas, de cuatro unidades tributarias mensuales; todo ello, sin perjuicio de que en determinadas infracciones, atendida su gravedad, se contemplen multas de cuantía superior" (artículo 25). De esta forma, es posible establecer un cierto rango de las multas que permite vincular con al régimen de prescripción de los delitos. Así, las faltas estarían asociadas a multas que no sobrepasen las 4 unidades mensuales y tendrían un plazo de prescripción de 6 meses; mientras que los simples delitos tendrían multas de hasta 20 unidades tributarias mensuales y con un plazo de prescripción de 5 años. Por último, estarían los crímenes con multas entre 20 y 30 unidades tributarias mensuales, con un plazo de prescripción que por regla general es de 10 años.

Ahora bien, el problema de adoptar esta segunda opción es que no se trata de una pena principal, sino que de una pena de carácter común. Además, el plazo de prescripción de los crímenes comprende un período de 10 años, que parece ser del todo excesivo, pues el legislador está pensado en la pena principal más que en la multa.

En definitiva, de estos dos caminos, parece más apropiado entender que el plazo general en materias de infracciones administrativas viene dado desde la legislación municipal y de policía (6 meses), y que en un nivel superior se podría extender a un plazo de 5 años tratándose de sanciones que sean de monto superior, conforme a la regla de los simples delitos ${ }^{92}$.

Por su parte, un criterio similar se plantea en el caso de la prescripción de las sanciones administrativas, aunque con un matiz que es importante. En efecto, si bien también resulta aplicable el criterio general de los 6 meses, conforme a la regla prevista en la legislación municipal, el plazo máximo no debiera exceder de los efectos que puede producir

\footnotetext{
92 En parte esta fue la solución dada por el Ministro Sergio Muñoz en el voto de minoría CORPBANCA CON SUPERINTENDENCIA DE BANCOS E INSTITUCIONES FINANCIERAS (2017) (considerando 17o del voto de minoría).
} 
un acto administrativo en cuanto título ejecutivo, esto es, tres años. Para sostener aquello, debemos recordar que el acto administrativo es un acto de autoridad, que causa inmediata ejecutoriedad y autoriza su ejecución de oficio por parte de la propia Administración, en la medida que lo establezca la ley (artículo $3^{\circ}$ de la Ley $N^{o}$ 19.880). En los casos en que no exista una regulación especial, aparece lo que se conoce como ejecutoriedad impropia, es decir, aquellos supuestos en que el acto no produce sus efectos por sí mismos, y requiere la intervención de otra autoridad administrativa o la intervención judicial. En este último caso es en donde el acto administrativo aparece como un título ejecutivo, ya sea que contenga una multa o reconozca alguna obligación pecuniaria. Por otra parte, diversos preceptos confieren expresamente mérito ejecutivo a determinados actos administrativos ${ }^{93}$, sin perjuicio que el artículo 434 No 7 del Código de Procedimiento Civil señala que el juicio ejecutivo tiene lugar en las obligaciones de dar cuando para reclamar su cumplimiento se hace valer, entre otros títulos, "Cualquiera otro título a que las leyes den fuerza ejecutiva" Desde tal perspectiva, y conforme a lo dispuesto en el artículo $3^{\circ}$ inciso final de la Ley No 19.880, el acto administrativo goza de fuerza ejecutiva. En esa misma línea, conforme a los artículos 442 del Código de Procedimiento Civil y 2.515 del Código Civil, en relación con su artículo 2.514, se establece que las acciones ejecutivas prescriben en tres años, contados desde que la obligación se hace exigible, regla plenamente aplicable a las sanciones administrativas, como lo ha reconocido la jurisprudencia de Contraloría ${ }^{95}$.

\section{CONCLUSIONES}

En esta investigación nos hemos propuesto encontrar criterios de solución al problema de la falta de regulación de la prescripción de las infracciones y sanciones administrativas, los cuales deben ser coherentes tanto al interior del régimen de poderes sancionadores de la Administración, como en relación con otros poderes punitivos del Estado.

Ahora bien, el fundamento de la prescripción en estos casos no difiere de lo que ocurre en otros ámbitos del ordenamiento: la seguridad y la certeza jurídica. Sin embargo, también se deben considerar la oportunidad y eficacia en el actuar de la Administración, pues el tiempo también hace decaer la necesidad del castigo de estas conductas en relación con el riesgo que generan. En este contexto, la prescripción es una forma de extinción de la responsabilidad administrativa, ya sea por el cumplimiento del plazo para su persecución o por no haber ejecutado la sanción. Esto determina algunas particularidades, debido al interés público comprometido, razón por la cual debe ser declarada de oficio por la autoridad administrativa o judicial, no puede ser renunciada, puede ser alegada sin límites dentro del

\footnotetext{
93 Artículos 174 del Código Sanitario; 7 de la Ley No 21.000 y 37 del Decreto Ley No 3.063.

94 Por su parte, y de conformidad a lo dispuesto en los artículos 530 y siguientes del citado Código, hay acción ejecutiva en las obligaciones de hacer, cuando, siendo determinadas y actualmente exigibles, se hace valer para acreditarlas algún título que traiga aparejada ejecución de conformidad al artículo 434, dentro de los cuales, se encontraría el acto administrativo terminal. Las mismas disposiciones son aplicables tratándose de obligaciones de no hacer en los términos previstos en el artículo 544 del mismo Código.

95 Dictámenes N ${ }^{\text {os }} 98.032$ (2015); 16.164, 30.871, 46.766 y 50.097, todos de (2016).
} 
procedimiento administrativo o judicial y configura la ilegalidad de una sanción que soslaya su aplicación.

En general, los ordenamientos comparados la prescripción exige de una determinación legal, asumiendo un tratamiento diverso entre la prescripción de las infracciones y las sanciones administrativas. Además, se tiende a utilizar como referencia la regulación penal y plazos que varían en cuanto a la gravedad de la sanción. En cambio, en Chile no contamos con una regulación general y la legislación sectorial omite diversos aspectos relevantes (suspensión, interrupción, caducidad del procedimiento, plazos).

En este contexto, la proporcionalidad juega una tarea fundamental en la determinación del plazo de prescripción. Se trata de un principio que se encuentra en las bases históricas del Derecho administrativo, sin perjuicio de su adopción en el Derecho penal y Constitucional, razón por la cual se impone respecto del ejercicio de poderes sancionadores por parte de los órganos administrativos, como lo ha reconocido nuestra doctrina y la jurisprudencia.

La tesis central de este trabajo, es que el plazo de prescripción está condicionado por la gravedad de la infracción. A su vez, el elemento que permite establecer esta gravedad se debe encontrar en la pena o sanción que el propio legislador le asigna. En efecto, aquella constituye el único criterio objetivo que nos podrá indicar cuál es el grado de desvalor que le asigna el ordenamiento jurídico a determinada conducta y, al mismo tiempo, es el único elemento de comparación. Además, la gravedad de la sanción también determina la intensidad de las garantías que tendrá el particular frente al Estado.

En Chile se ha buscado la solución en la aplicación de las reglas de prescripción de las faltas penales o, en su caso, en las normas del Código Civil, en una disputa por resolver un problema más profundo en relación con la naturaleza y régimen aplicable a las infracciones administrativas. Sin embargo, en nuestra opinión este resultado no es satisfactorio, porque en uno y otro caso se llega a un tratamiento uniforme de todas las infracciones administrativas (6 meses o 5 años), omitiendo la diversa gravedad que el propio legislador les ha reconocido.

Conforme a lo expuesto, la solución al tema exige algunos criterios de referencia básicos, como la necesidad de que exista un plazo de prescripción (no pueden existir infracciones imprescriptibles); que dicho plazo sea establecido por ley y que en su aplicación se debe respetar el principio de proporcionalidad, ya que no es constitucionalmente admisible establecer un plazo uniforme sin considerar la gravedad de las mismas. De acuerdo a estas premisas, la solución en estos casos nos lleva a una coordinación entre la legislación administrativa y penal, que parece el ámbito más apropiado para resolver estos asuntos, en relación con la legislación civil. Además, su tronco histórico se encuentra en las normas de policía, en su gran medida desarrolladas en el ámbito municipal y de policía. Por otra parte, el Código Penal también regula el plazo de prescripción de las multas, que es la principal sanción que se aplica en sede administrativa.

En definitiva, ante estas dos opciones, consideramos más apropiado entender que el plazo general en materias de infracciones administrativas viene dado desde la legislación municipal (6 meses), y que en un nivel superior se podría extender a un plazo de 5 años tratándose de sanciones que sean de monto superior, conforme a la regla de los simples delitos. 
Un criterio similar se plantea en el caso de la prescripción de las sanciones administrativas, aunque con un matiz que es importante. En efecto, si bien también resulta aplicable el criterio general de los 6 meses, el plazo máximo no debiera exceder de los efectos que puede producir un acto administrativo en cuanto título ejecutivo, esto es, tres años.

En definitiva, la necesidad de encontrar puntos de referencia que nos permita entregar al operador jurídico elementos para resolver un vacío legal de enorme envergadura, nos lleva a entregar una solución que, según nuestra opinión, guarda mayor conformidad con el marco constitucional y, particularmente, con el principio de proporcionalidad.

\section{BIBLIOGRAFÍA CITADA}

Arnold, Rainer; MartíneZ, José Ignacio y ZúñIga, Francisco (2012): "El principio de proporcionalidad en la jurisprudencia del Tribunal Constitucional”, Estudios Constitucionales, Vol. 10, No 1: pp. 65-116.

AA.VV. (1982): Le sanzioni amministrative (Atti del XXVI Convegno di Studi di Scienza dell'Amministrazione, Varenna, 18-20 settembre 1980 (Guiffrè, Milano).

AA.VV. (2018): Karlsruher Kommentar zum Gesetz über Ordnungswidrigkeiten: OWiG (5. Auflage, C.H. Beck, München).

AlCALDE, Enrique (2013): La responsabilidad de los directores de sociedades anónimas (Santiago, Ediciones UC).

Amunátegui, J. Domingo (1894): Administración Politica i Derecho Administrativo (Santiago, Imprenta Cervantes).

Arancibia, Jaime (2014): "El principio de necesidad de la sanción administrativa como potestad de ultima ratio", en Arancibia, Jaime y Alarcón, Pablo, Sanciones Administrativas, X Jornadas de Derecho Administrativo (Santiago, Thomson Reuters).

Arnold, Reiner; MartíneZ, José Ignacio y ZúNíga, Francisco (2012): "El principio de proporcionalidad en la jurisprudencia del Tribunal Constitucional", Estudios constitucionales, Vol.10, No 1: pp. 65-116.

ArósticA, Iván (2005): "Sanciones Administrativas y prescripción”, en: AA.VV: Sanciones Administrativas y derechos fundamentales: regulación y nuevo intervencionismo (Universidad Santo Tomás), pp. 119-126.

BACA, Víctor (2011): La prescripción de las infracciones y su clasificación en la Ley de Procedimiento Administrativo General (en especial, análisis de los supuestos de infracciones permanentes y continuadas) (Derecho y Sociedad No 37), pp. 263-274.

Bon, Pierre y Maus, Dider (coor.) (2008): Les grandes décisions des cours constitutionnelles européennes (Paris, Dalloz).

Caballero, Rafael (1999): Prescripción y caducidad en el procedimiento administrativo (Madrid, McGraw-Hill Interamericana).

Caballero, Rafael (2010): "Prescripción de infracciones y sanciones", en Lozano, Blanca (Dir.), Diccionario de sanciones administrativas (Madrid, Iustel), pp. 641-666.

CAno, Tomas (2014): Las sanciones de tráfico (Navarra, Thomson Reuters-Aranzadi, 2a edición).

CarPentier, Elice (2009): "La utilización de la jurisprudencia constitucional extranjera por el Consejo Constitucional francés” Estudios Constitucionales, Vol. 7, No 2: pp. 129-142. 
Cerbo, Pasquale (2009): "Las sanciones administrativas en Italia: un problema de Derecho constitucional”, Documentación Administrativa, Nos. 282-283: pp. 61-90.

Cerezo, J. (1975): "Límites entre el Derecho penal y el Derecho administrativo", Anuario de Derecho penal y Ciencias penales, Tomo XXVIII, Fascículo II, pp. 159-173.

Cordero, Luis (2011): "El decaimiento del procedimiento sancionador. Comentarios de las sentencias de la Corte Suprema del año 2010”, Anuario de Derecho Público, Universidad Diego Portales: pp. 243-255.

Cordero, Eduardo y Aldunate, Eduardo (2012): "Las bases constitucionales de la potestad sancionadora de la Administración”, Revista de Derecho de la Pontificia Universidad Católica de Valparaíso, No 39: pp. 337-361.

Cordero, Eduardo (2014): Derecho Administrativo Sancionador (Santiago, Thomson Reuters).

Cordero, Eduardo (2014): "Los principios y reglas que estructuran el ordenamiento jurídico chileno", Revista Ius et Praxis, año 15, No 2: pp. 11-49.

Cordero, Eduardo (2019): "Los reglamentos como fuente del derecho administrativo y su control jurisdiccional”, Revista Ius et Praxis, año 25, No 1: pp. 285-334.

Covarrubias Cuevas, Ignacio (2018): "El Principio de Proporcionalidad en la jurisprudencia del Tribunal Constitucional Federal alemán: más allá de Alexy", Ius et Praxis, Vol. 24, No 3: pp. 477-524.

Cury, Enrique (2005): Derecho Penal. Parte General (Santiago, Universidad Católica de Chile, octava edición).

De Diego, L. Alfredo (2009): Prescripción y caducidad en el Derecho Administrativo Sancionador (Barcelona, Bosch, segunda edición).

De Palma del Teso, Ángeles (2001): "Infracciones administrativas continuadas, las infracciones permanentes, las infracciones de estado y las infracciones de pluralidad de actos", Revista Española de Derecho Administrativo, No 112: pp. 553-574.

Fernández Nieto, Josefa (2008): Principio de proporcionalidad y derechos fundamentales: una perspectiva desde el Derecho Público común Europeo (Madrid, Universidad Rey Juan Carlos).

García de Enterría, Eduardo (2016): La lucha contra las inmunidades del poder (Madrid, Civitas, 3d. ed.).

Gallardo, María Jesús (2008): Los principios de la potestad sancionadora. Teoría y práctica (Madrid, Iustel).

GarCía, Francisco (2007): Sanciones administrativas. Garantías, derecho y recursos del presunto responsable (Granada, Comares, tercera edición).

GARCíA, Magdalena (2013): "La prescripción vis a vis el "plazo razonable", Derecho administrativo sancionador. Notas sobre la doctrina de la especial sujeción. Disponible en: http:// www.saij.gob.ar/doctrina/dacf130184-garcia_rossi-prescripcion_vis_vis_plazo.htm

Giovangnoli, Roberto y Fratini, Marco (2009): Le sanzioni Admministrative (Milano, Guiffrè).

Gómez, Rosa Fernanda (2018): Discrecionalidad en el ejercicio de la potestad sancionadora de la Administración. Limites y mecanismos de control a su ejercicio, Tesis Doctoral, Pontificia Universidad Católica de Valparaíso. 
Gómez, Rosa Fernanda (2019): "Antecedentes históricos de la potestad sancionadora de la Administración en Chile", en Revista de Derecho del Estado (Colombia), № 44 (en prensas).

Guzmán, José Luis (2002): “Comentario al artículo 95”, en: Politoff, Sergio y Ortiz, Luis (dir.), Matus, Jean Pierre (coord.), Texto y comentario del Código Penal chileno, Tomo I, Parte General, (Santiago, Editorial Jurídica de Chile).

Huneeus, Jorge (1891): La Constitución ante el Congreso, Vol. 3 (Santiago, editorial Cervantes, Segunda edición).JAKOBS, Günther (1997): Derecho penal. Parte general. (Marcial Pons, Madrid, 2a edición).

KLuTH, Winfried (1998): "Prohibición de exceso y principio proporcionalidad en Derecho Alemán”, Cuadernos de Derecho público, vol. 5: pp. 219-237.

KRAUSS Ruprecht von (1955): Der Grundsatz der Verhältnismässigkeit in seiner Bedeutung für die Notwendigkeit des Mittels in Verwaltungsrecht (Appel in Komm, Hamburg).

Letelier, Valentín (1907): Apuntaciones de Derecho Administrativo (Santiago, Imprenta i Encuadernación Chile).

LeRCHE, Peter (1961): Übermass und Verfassungsrecht (Heymann, Köln).

Lopera, Gloria Patricia (2011): "Principio de proporcionalidad y control constitucional de las leyes penales. Una comparación entre las experiencias de Chile y Colombia,", Revista de Derecho (Valdivia), vol. XXIV, No 2: pp. 113-138.

LozANO, Blanca (1990): La extinción de las sanciones administrativas y tributarias (Madrid, Marcial Pons).

Malagón, Miguel (2004): "La Ciencia de la Policía y el Derecho administrativo", Estudios Socio-Jurídicos, vol. 6, No 1: pp. 174-210.

Mayer, Otto (1982): Derecho Administrativo Alemán (Buenos Aires, Depalma).

Mayer, Max Ernst (2007): Derecho Penal. Parte General (Traducc. Sergio Politoff, Buenos Aires, Euros Editores; Montevideo, Bdef, edición alemana de 1913 "Der allgemeine Teil des deutschen Straftrechts”, Carl Winters Universitätsbuchhandlung, Heidelberg).

MendozA, Ramiro (2005): "Acerca del principio general de la intransmisibilidad de las multas en particular cuando ellas no se encuentran ejecutoriadas", en: AA. VV. Sanciones Administrativas y Derechos fundamentales: regulación y nuevo intervencionismo. (Universidad Santo Tomás), pp. 127-153.

Mestre, Juan Francisco (1991): "La configuración constitucional de la potestad sancionadora de la Administración Pública", en Estudios sobre la Constitución española. Homenaje al profesor Eduardo García de Enterría, Vol. III. (Madrid, Civitas), pp. 2493-2528.

Nieto, Alejandro (2012): Derecho Administrativo Sancionador (Madrid, Tecnos, 5a edición).

Nieto , Alejandro (1976): "Algunas precisiones sobre el concepto de policía", Revista de Administración Pública, No 81: pp. 35-75.

Osorio, Cristóbal (2018): Manual de Procedimiento Administrativo Sancionador. Parte General (Santiago, Thomson Reuters).

Osterling, Felipe y Castillo, Mario (2004): “Todo Prescribe o Caduca, a menos que la Ley señale lo contrario", Derecho y Sociedad, No 23: pp. 267-274.

Prado, Santiago (1859). Principios elementales de Derecho Administrativo chileno: adaptados a la enseñanza del ramo en el Instituto Nacional siguiendo el plan I las teorías de varios autores (Santiago, Imprenta Nacional). 
Quintero, Gonzalo (1982): “Acto, resultado y proporcionalidad”, Anuario de Derecho Penal y Ciencias Penales, T. XXXV, Fasc. II, Mayo-Agosto: pp. 381-408.

REMMERT, Barbara (1995):Verfassungs- und verwaltungsrechtsgeschichtliche Grundlagen des Übermassverbotes (C.F. Müller, Heidelberg).

RodrígueZ, Luis (1987): "Bases para distinguir entre infracciones criminales y administrativas", Revista de Derecho (Valparaíso), No 11: pp. 117-163.

Roxin, Claus (1997): Derecho penal. Parte general. Tomo. I (Madrid, Editorial Civitas).

SÁnchez, Miguel (2016): Derecho Administrativo. Parte General (Madrid, Tecnos, 19a edición).

SCHWABE, Jürgen (2009): Jurisprudencia del Tribunal Constitucional Federal Alemán (Berlín, Konrad-Adenauer-Stiftung).

Soto Kloss, Eduardo (1984): "Prescripción extintiva de derechos de los administrados y cumplimiento de obligaciones legales impuestas a la Administración”, Revista Chilena de Derecho, vol. 11: pp. 505-517.

VALlejo, Rodrigo (2016): "Acerca del régimen supletorio de prescripción aplicable a las infracciones y sanciones administrativas", Revista de Derecho (Valparaíso), No 47: pp. 281-301.

VARGAS, Juan Enrique (1987): La extinción de la responsabilidad penal (Santiago EdiarConosur).

\section{JURISPRUDENCIA CITADA}

CORTE SUPREMA

Aedo Alarcón, Paulina con Fisco (2000): 27 de noviembre (casación en el fondo). Rol No 852-2000.

ALBALA Y OTRA CON ISP DE CHILE (2015): 21 de septiembre (casación en el fondo). Rol No 3.528-2015.

BANCO DE CHILE CON UNIDAD DE ANÁLISIS FinANCIERo (2018): 17 de abril (reclamación). Rol No 38.857-2017.

BECERRA CON REYES (2012): 30 de agosto (casación en el fondo). Rol No 6.109-2010.

CARVAJAL Y OTROS CON VEGA Y OTROS (2012): 11 de julio (casación en la forma y en el fondo). Rol No 8.879-2010.

Casino de Juegos Temuco S.A. con Superintendencia de Casinos de Juegos (2018): 8 de enero (casación en el fondo). Rol No 2.961-2017.

Compañía Eléctrica del Litoral S.A. con Superintendencia de EleCtricidad y Combusti$B L E S$ (2010): 20 de octubre (reclamación). Rol No 5.228-2010.

Compañía Minera Zaldivar Limitada con Secretaria Regional Ministerial de Salud (2018): 28 de agosto (casación en el fondo). Rol No 8420-2017.

ZuCCHINo AGUiRRe y OtRos (2014): 13 de enero (casación en el fondo). Rol No 4024-2013.

Corpanca con Superintendencia de BANCOS E Instituciones FinanCiERAS (2017): 9 de mayo. Rol No 62.128-2016,

Dirección General de Aguas con Sociedad Alto Atacama S.A. (2013): 25 de noviembre (apelación). Rol No 7.559-2012.

EMPRESA CONSTRUCTORA GATICA LTDA. CON FISCO Y OTRA (2005): 27 de abril (casación en el fondo). Rol No 4.727-2003. 
EMpresa ElÉCtrica de Antofagasta S.A con SuperintendenCIA DE ELECTRICIDAd Y CombustiBLES (2009): 10 de septiembre (reclamación). Rol No 3.357-2009.

EMPRESA ELÉCTRICA DE AYSÉN S.A. EDELAYSÉN CON SUPERINTENDENCIA DE ELECTRICIDAD Y COMBUSTIBLES (2009a): 3 de agosto(reclamación).

Empresa Eléctrica de Aysén S.A. Edelaysén con Superintendencia de Electricidad y Combustibles (2009b): 3 de agosto (reclamación).

EyzaguirRe Cid, GERMÁn CON FisCo DE ChILE (2007): 28 de junio (casación en el fondo). Rol No 1.203-2006.

FARAH CON SuperintendenCIa DE VALORES y SEGUROS (2016): 24 de agosto (casación en la forma y en el fondo).

FISCO CON DORR ZEGERS Y OTROS (2014): 30 de octubre (casación).

FisCO CON IRARRÁZABAL (2016): 21 de julio (casación en el fondo). Rol No 37.054-2015.

Forestal Celco S.A. con Superintendencia de Electricidad y Combustibles (2015): 30 de junio (reclamación). Rol No 4.503-2015.

FRontel S. A. CON SuperintendenCIA DE ELECTRICIDAD Y Combustibles (2010): 28 de enero (reclamación). Rol No 7.502-2009.

Fuentes CON SEREMI de SALUd REGión del MAULE (2005): 28 de abril (acción de amparo). Rol No 1813-2005.

GUERRERO CON BERSANO Y OTRO (2017): 14 de julio (casación en la forma y en el fondo). Rol No $11.085-2015$.

Industria Frigorífica Simunovic S.A. con Comisión de EVALUaCión Ambiental de MagallaNES Y ANTÁRTICA (2014): 18 de agosto (casación en el fondo). Rol No 14.432-2013.

ISP CON LABORATORIOS RECALCINE S.A. (2010): 9 de abril (reclamación).

Bustos, José SAN MARTÍN CON FisCo DE ChILe (2020): 2 de marzo (casación en el fondo). Rol No 29167-2019.

LABORATORIO MAVER LIMITADA CON ISP (2011): 26 de julio (apelación).

LABORATORIOS LAFI CON ISP (2018): 23 de octubre (casación en el fondo). Rol No 44.5102017.

LABORATORIOS RECALCINE S.A. CON ISP (2011): 22 de septiembre (reclamación). Rol No 6.068-2009.

LABORATORIOS RECALCINE S.A. CON ISP (2012): 9 de abril (reclamación). Rol No 78-2010.

LABORATORIOS RECALCINE S.A. CON ISP (2012): 9 de abril (reclamación). Rol No 134-2010.

LABORATORIOS RECALCINE S.A. CON ISP (2013): 25 de noviembre (reclamación).

LABORATORIOS RECALCINE S.A. CON ISP (2013): 17 de junio (reclamación). Rol No 9.1862012.

LuzLinares S.A. con SuperintendenCIA DE EleCtRicidad Y Combustibles (2010): 16 de septiembre (reclamación). Rol No 4.923-2010.

LuzParral S.A. con Superintendencia de Electricidad Y Combustibles (2010): 15 de septiembre (reclamación). Rol No 4.922-2010.

PiÑONES VEGA, MARGARITA Y OtROS (2020): 9 de marzo (casación en el fondo). Rol No 3982018.

MARTINS Y OTRA CON ISP (2010a): 2 de abril (reclamación). Rol No 2501-2010.

MARTINS Y OTRA CON ISP (2010b): de 2 de abril (reclamación). Rol No 2563-2010. 
Opko Chile S.A y Alegría Madrid con Instituto de Salud Pública (2019): 10 de septiembre (casación en el fondo). Rol No 16.230-2018.

Ortega Fuentes, MARÍa ISABEL CON FisCO DE ChILE (2010): 8 de abril (casación en el fondo). Rol No 2080-08.

Oyarzún con Sociedad Pesquera del Mar Antártico S.A. (2015): 19 de agosto (casación en el fondo). Rol No 23.182-2014.

Pharmamérica Limitada CON ISP (2017): 23 de noviembre (reclamación). Rol No 12.1642017.

PIZANI Y OTRA CON FISCO (2003): 15 de abril (casación en el fondo). Rol No 1.234-2002.

Promaq Ingeniería y Construcción Limitada con Secretaría Regional Ministerial de SALUD dE la REGIÓN MEtropolitana (2017): 22 de noviembre (reclamación). Rol No 100.727-2016.

SCHENKE CON SERVICIO DE SALUD (2002): 15 de octubre (acción de amparo). Rol No 39252002.

SheLl CON SuperintendenCia de ELECTRICIDAD y Combustibles (2009): 28 de diciembre (reclamación).

Sistema TRansmisión del Sur S.A. con Superintendencia de EleCtricidad y Combustibles (2010): 28 de enero (reclamación). Rol No 7.284-2009.

ZEGERS CON SUPERINTENDENCIA DE VALORES Y SEGUROS (2013): 13 de junio (reclamación).

Corte de Apelaciones de Santiago

Compañía de Telecomunicaciones de Chile S.A. con Ministerio de Transportes y TelecoMUNICACIONES (2012): 27 de enero (apelación). Rol No 8.151-2011.

TRIBUNAL CONSTITUCIONAL

Honorable CAmara de Diputados (1996). 26 de agosto (control de constitucionalidad del proyecto de ley, aprobado por el Congreso Nacional, enviado por la Cámara de Diputados y que modifica la ley No 4.601, Ley de Caza, a fin de proteger la fauna) Rol No 244.

Honorable Camara de Diputados (2007). 13 de junio (requerimiento de inaplicabilidad por inconstitucionalidad). Rol No 786

GATICA Y OTRA CON SOTO (2010). 3 de marzo (requerimiento de inaplicabilidad por inconstitucionalidad). Rol No 1.298.

SANCHEZ Y OTROS CON SEREMI SALUD (2010). 21 de octubre (requerimiento de inaplicabilidad por inconstitucionalidad). Rol No 1.518 .

VARgas con Ministerio Público (2018). 6 de noviembre (requerimiento de inaplicabilidad por inconstitucionalidad). Rol No 4.802.

Gallardo con Ministerio Público (2017). 27 de marzo (requerimiento de inaplicabilidad por inconstitucionalidad). Rol No 2.995.

\section{CONTRALORÍA}

Dictamen No 97.010, de 1965. 
Dictamen No 80.098, 31 de octubre de 1972.

Dictamen No 52.562, agosto de 1975.

Dictamen No 40.050, 7 de diciembre de 1981.

Dictamen No 35.991, 24 de noviembre de 1982.

Dictamen No 16.159, 28 de junio de 1993.

Dictamen No 14.571, 22 de marzo de 2005.

Dictamen No 28.226, 22 de junio de 2007.

Dictamen No 30.070, 1 de julio de 2008.

Dictamen No 18.353, 9 de abril de 2009.

Dictamen No 68.014, 22 de octubre de 2013.

Dictamen No 44.905, 15 de julio de 2013.

Dictamen No 53.050, 10 de agosto de 2013.

Dictamen No 41.239, 10 de junio de 2014.

Dictamen No 27.123, 16 de abril de 2014.

Dictamen No 29.021, 24 de abril de 2014.

Dictamen No 98.032, 11 de diciembre de 2015.

Dictamen No 26.724, 11 de abril de 2016.

Dictamen No 16.164, 1 de marzo de 2016.

Dictamen No 30.871, 25 de abril de 2016.

Dictamen No 46.766, 24 de junio de 2016.

Dictamen No 50.097, 6 de junio de 2016.

Dictamen No 24.731, de 12 de septiembre de 2019.

\section{NORMAS CITADAS}

Código Civil, DFL No 1, del Ministerio de Justica, de 2000, que fija su texto refundido, coordinado y sistematizado.

Código de Procedimiento Civil (30/8/1902).

Código Penal (12/11/1874).

Código Sanitario (31/1/1968).

DFL No 1/1994 (26/10/1994), del Ministerio de Hacienda, que establece el texto refundido, coordinado y sistematizado del estatuto orgánico del Servicio de Tesorería.

DFL No 3/1997 (19/12/1997), del Ministerio de Hacienda, que fija el texto refundido, coordinado y sistematizado de la Ley General de Bancos

Decreto Ley No 3.063 (20/11/1996), sobre Rentas Municipales.

LEY No 16.395 (28/01/1966), que fija el texto refundido de la Ley de Organización y atribuciones de la Superintendencia de Seguridad Social.

LEY No 18.410 (22/5/1985), que crea la Superintendencia de Electricidad y Combustibles.

LEY No 18.834 (23/9/1989), que aprueba el Estatuto Administrativo.

LEY No 18.902 (27/1/1990), que crea la Superintendencia de Servicios Sanitarios.

LeY No 19.175 (8/11/2005), Orgánica Constitucional de Gobierno y Administración Regional. 
CORDERO Q., Eduardo — "El plazo en la prescripción de las infracciones y sanciones administrativas ..."

Ley No 19.880 (9/5/2003), que establece las Bases de los Procedimientos Administrativos que rigen los actos de los Órganos de la Administración.

LEY No 19.995 (7/1/2005), que establece las bases generales para la autorización, funcionamiento fiscalización de casinos de juegos.

LEY No 20.417 (26/1/2010), que crea el Ministerio, el Servicio de Evaluación Ambiental y la Superintendencia de Medioambiente.

LEY No 20.529 (27/8/2011), sobre el Sistema Nacional de aseguramiento de la calidad de la educación parvularia, básica y media y su fiscalización.

LEY No 20.720 (9/1/2014), que sustituye el Régimen Concursal vigente por una Ley de Reorganización y Liquidación de Empresas y Personas, y perfecciona el rol de La Superintendencia del Ramo.

Ley No 21.000 (23/2/2017), que crea la Comisión para el Mercado Financiero. 